\title{
The effect of set on categorization in visual search
}

\author{
HENRY GLEITMAN \\ University of Pennsylvania, Philadelphia, Pennsylvania 19104 \\ and \\ JOHN JONIDES \\ University of Michigan, Ann Arbor, Michigan 48104
}

\begin{abstract}
Two experiments examine whether set for a categorial difference or set for a target category is necessary in order to obtain the category effect in visual search. Eliminating a set for categorial difference does not diminish the size of the effect. When subjects are prevented from developing a useful set for the target category, however, the category effect is eliminated.
\end{abstract}

By now, many studies of visual search performance have demonstrated a category effect when alphanumeric characters are used as target and field items. Target items are detected faster and more accurately in a between-category condition in which the field items are drawn from a different category (e.g., a "4" among letters) than they are in a within-category condition in which all array items belong to the same category (e.g., a "B" among other letters). Much of the relevant evidence comes from studies in which subjects have to detect the presence of a target among a number of field items in a small array, all presented too briefly to permit an eye movement (Egeth, Jonides, \& Wall, 1972; Gleitman \& Jonides, 1976; Jonides \& Gleitman, 1972, 1976). Similar effects have been obtained with other experimental paradigms, such as scanning (e.g., Brand, 1971; Ingling, 1972; Sperling, Budiansky, Spivak, \& Johnson, 1971) and samedifferent discrimination (e.g., Posner, 1970).

To account for the category effect. Gleitman and Jonides (1976) have suggested a "partial processing" hypothesis, according to which categorization (e.g., deciding whether a given item is a digit) requires less detailed extraction of featural information than does identification (e.g., deciding whether an item is a "4"). According to this hypothesis, the features analyzed during between-category search are either fewer in number or are somehow "easier" to extract than are those required for within-category search. One way of investigating this hypothesized mechanism would be to search for the actual physical

We wish to thank Chris Foard for a valuable discussion of the general paradigm employed in these experiments. This research was supported by a Rackham Faculty Research Grant and by National Science Foundation Grant BNS77-16887, both to John Jonides. features that distinguish among alphanumeric characters. But this would be a difficult enterprise, considering how little is known about these features, both between and within categories. Gleitman and Jonides (1976) and Jonides and Gleitman (1976) chose a more direct approach: they tested some implications of the partial processing hypothesis without making any specific commitments about the actual features that are involved in this processing. Among other things, they showed that partial processing has both a benefit and a cost. The benefit is conferred by allowing the between-category searcher to locate the target without first identifying all of the distractor items. The result is faster and more accurate detection (Jonides \& Gleitman, 1976). The cost is incurred because between-category search leads to a more shallow analysis of the target: less information is registered and/or retained about both targets and field items during between- than during within-category search (Gleitman \& Jonides, 1976).

The difficulty with the partial processing hypothesis is that it has to account for a further phenomenon. When the field items are letters and subjects are asked to search for the letter $O$, they generate RT functions characteristic of within-category search. When presented with the identical array and asked to search for the very same target which, however, is now described as the digit "zero," they produce RT functions of much lower slope characteristic of between-category search (Jonides \& Gleitman, 1972). This effect demonstrates that subjects' search performance does not only depend upon the physical stimulus; it is also influenced by the experimental instructions. (For related findings see Ingling, 1972, and Keren, 1977).

How can the partial processing hypothesis handle the oh-zero effect? A further assumption is required. 
One must suppose that subjects can, as it were, choose to process either fully or partially. The strategy adopted should then depend upon whether they expect to be presented with within- or betweencategory trials, respectively. Our first experiment tests this assumption.

\section{EXPERIMENT 1}

The first experiment asks whether advance knowledge of the categorial difference in the display contributes to the appearance of a category effect. Perhaps the most straightforward test would be one in which within- and between-category trials are randomly intermixed. The subjects would always be told which target to look for. On half of the trials, they would be preinformed of the category of the field items; on half, they would have no such advance knowledge. If the size of the category effect were the same on informed as on uninformed trials, then a set for the categorial relationship between target and field items would seem to be irrelevant.

The trouble is that such a result would be far from conclusive. After all, the subjects would know that half of the trials were of the between-category type and therefore might adopt the strategy of partially processing the array items even on uninformed trials. If this failed to reveal a target, they could then switch to a strategy of fully identifying each array item. Thus, there might well be a category effect under both informed and uninformed conditions. ${ }^{1}$

The trick is to prevent subjects from having any foreknowledge that they will ever encounter a between-category trial. To this end, we adopted the following experimental design. All subjects first received 112 within-category trials: they looked for one of two targets, say either a D or a K among a number of other letters. On the 113th trial, the subjects were given an unexpected between-category trial: the array consisted of, say a D among a number of digits. The subjects' performance on this one trial could not possibly be attributed to a set for a categorial difference. After all, there was no reason for them to suspect that the 113 th trial would be any different from the 112th.

To assess the presence and magnitude of the category effect on the crucial 113th trial, we compared the performance on that trial with performance on the immediately preceding withincategory trials. We also compared it with performance on 96 between-category trials presented immediately thereafter.

All between-category trials after the crucial unexpected one occurred with the subjects' foreknowledge.

\section{Method}

Subjects. The 16 subjects whose data were included in the analysis were female undergraduates who were paid for participation in a $40-\mathrm{min}$ session. Eight other female undergraduates were excluded due to excessively high error rates.

Apparatus. The stimuli were presented in an Iconix mirror tachistoscope, Model 6137-4. Prior to each trial, the subjects were asked to fixate a black dot centered on a blank screen $(15.5 \mathrm{~mL})$. They initiated each trial by depressing a foot pedal. A half-second later, a stimulus card appeared for $200 \mathrm{msec}$, followed by a masking field constructed of pieces of letters and digits. The masking field remained in view for $1 \mathrm{sec}$, after which the fixation dot reappeared and remained for an intertrial interval of about $5 \mathrm{sec}$.

Stimulus materials. The stimulus cards were constructed using a procedure adapted from that of Eriksen and his colleagues (e.g., Eriksen \& Rohrbaugh, 1970), and later modified by Egeth, Jonides, and Wall (1972). The stimulus items were black Letraset numerals and uppercase letters (Futura Demi-bold, 24-point, $.32^{\circ}$ in height). Both target and field items were located around the circumference of an imaginary circle whose diameter was $3.4^{\circ}$ and whose center coincided with the position of the fixation point. The item loci were chosen from among eight equally spaced positions around this imaginary circle. Two display sizes were used: two and five items. When two items appeared on a stimulus card, they were placed at diametrically opposite locations on the circle. When five items appeared, at least two were diametrically opposed (the target and one field item if a target was present, or two field items if no target was present); the remaining items were randomly placed. Targets appeared equally often at each of the eight locations.

All subjects received the same sequence of stimulus cards. They were first given 112 within-category trials, the first 16 of which were considered practice trials and disregarded in the subsequent analysis. The 96 within-category test trials were randomly divided into two equal blocks of 48 . On half of the trials within each block, a target was present along with either one or four items: on the other half, no target appeared but there were either two or five field items. The targets were chosen from among the items $D, K$, and $P$ or 3,4 , and 9 ; the field items were chosen from the set $\mathrm{C}, \mathrm{E}, \mathrm{H}, \mathrm{N}$, and $\mathrm{S}$ or the set $2,5,6,7$, and 8 . When a target appeared, the field item(s) were chosen from the same category as the target; when no target appeared, all field items were chosen from the same category. Over all the 96 test trials, each target appeared equally often.

Immediately subsequent to the within-category trials, the subjects received 113 between-category trials. The first of these occurred without foreknowledge of the category conditions; for all subsequent 112 between-category trials, the subjects were appropriately preinformed. The 16 trials subsequent to the unexpected one were considered as practice trials and were disregarded from the subsequent analysis.

The 96 between-category test trials (randomly divided into two equal blocks) were constructed according to the same general principles as were the within-category trials. The only difference was that on trials on which a target appeared, the field item(s) were chosen from the category opposite that of the target. When no target appeared, all field items were chosen from the same category.

For both within- and between-category conditions, two targets were verbally specified before each trial. These changed (more or less randomly) from trial to trial, but both items were always drawn from the same target category on a trial (e.g., "press the button if you see a D or a $K$ "). For trials on which no target was actually present on the stimulus cards, the two specified targets were randomly drawn from the appropriate target set (of the same category as the field items for within-category trials and of the opposite for between-category trials). The subjects were told that when a target was present it would be one of the two specified, with either the first or the second equally likely.

The 16 practice trials that preceded the within-category condition, and the 16 that preceded the between-category condition 
were constructed according to the principles outlined above.

For the unexpected between-category trial that immediately followed the last within-category block, 16 different cards were constructed, 1 for each subject. Half were display size 2 , half display size 5; on half, the target that appeared was the first of the two specified; on half, it was the second. In all respects, these cards were similar to the standard 96 between-category cards used in the experiment.

Immediately after the last block of between-category trials, the subjects were given a "catch trial," as defined by Gleitman and Jonides (1976). The catch trial contained four field items and a member of the target set, but the target was neither of the two specified for that trial. It was, rather, the remaining member of the target category from which the two specified targets were drawn. Thus, for example, a subject might be told to look for a $D$ or a $K$ among digits, but instead would encounter a $\mathbf{P}$ among digits. As Gleitman and Jonides (1976) have shown, performance on such a catch trial is a good index of the category effect. Between-category subjects overwhelmingly react with a "yes" response, while within-category subjects rarely do so. It is as if between-category search represents search for any member of a given category rather than for the presence of a specific item. This between-category catch trial was included in the present experiment to provide an additional check on whether a categoryeffect would occur under the experimental conditions.

Sixteen different cards were used for the catch trials, one for each subject. All cards used a display size of five, and overall each target appeared equally often.

Procedure. At the beginning of the experiment, the subjects were familiarized with the targets and field items to be used in the experiment. They were informed about the randomly varying display size and about the fact that one of the two specified targets would be present on $50 \%$ of the trials. The subjects were told to respond as quickly but as accurately as possible by pressing a telegraph key when a target was present and not to respond when no target appeared. Finally, they were told that although items of either category might appear on different trials, the category of the specified target would always be the same as the category of the display items (i.e., they were given within-category instructions).

After the within-category trials were completed, and after the unexpected between-category trial was presented, the subjects were then given instructions appropriate to the between-category condition. That is, they were told that the field items would always be chosen from the category opposite to that of the specified targets. They were then given the 112 between-category practice and test trials, followed by the catch trial. ${ }^{2}$

Eight subjects were replaced because they failed to meet the error criterion of $7.5 \%$ on both the within- and between-category trials. These subjects averaged $9.8 \%$ and $6.4 \%$ errors on these types of trials, respectively (SDs were $3.3 \%$ and $2.5 \%$, respectively).

\section{Results and Discussion}

The analysis is presented in two parts. First, we ask whether the usual category effect is obtained on the standard within- and between-category trials. We then ask whether a category effect is also shown on the unexpected between-category trial (Trial 113), where the subjects had no foreknowledge of the categorial difference contained in the display. All calculations (in this and the following experiment) exclude RTs above and below 2.5 SD of the mean for each subject in each condition.

Standard within- and between-category trials. The data contain several different indications that the usual category effect was present. One line of evidence concerns the RT functions. These were obtained by plotting RT against display size for each subject in each of the two categorial conditions. The means and standard deviations of the slopes and intercepts of these RT functions are displayed in Table 1. As the table shows, the slope is considerably larger under the within- than under the between-category condition $[\mathrm{t}(15)=3.27, \mathrm{p}<.01]$. This slope difference is the hallmark of the category effect in this experimental paradigm. The difference in intercepts is not statistically significant $[\mathrm{t}(15)=$ $1.76, \mathrm{p}>.05$ ].

The greater processing difficulty of the withincategory condition is indicated not only by the greater slopes that it produces, but also by the fact that it leads to higher error rates. The means and standard deviations of the error rates for both categorial conditions are shown in Table 1 . The difference is reliable $[\mathrm{t}(15)=2.85, \mathrm{p}<.02]$.

Other evidence that bears on the presence of a category effect concerns the role of the serial position in which the targets were specified. Gleitman and Jonides (1976) have reported that the firstspecified target in a within-category condition is detected faster than the second-specified target; they found no such serial position effect in the betweencategory condition. The present data point in the same direction, although not reliably so. In the within-category condition, RTs were shorter when the stimulus card contained the first-specified target rather then the second $(585$ vs. $620 \mathrm{msec}$, respectively). In the between-category condition, this difference was much smaller ( 545 vs. $554 \mathrm{msec}$ ). However, the interaction with categorial condition is not significant $[\mathrm{F}(1,15)=2.04, \mathrm{p}>.10]$.

Yet another piece of evidence comes from the results of the catch trial that was given at the very end of the session. In these catch trials, the subject was told to look for, say, a 3 or a 9 among letters; in fact, the display contained a 4 among letters. Of the 16 subjects, 12 gave a "yes" response, a result consistent with earlier findings (Gleitman \& Jonides, 1976). The mean RT of these responses was not reliably different from the mean of the responses to display size 5 in the preceding betweencategory trials $[\mathrm{t}(11)=.77, \mathrm{p}>.10]$. Most subjects

Table 1

Means and Standard Deviations for Slopes (Milliseconds per Character), Intercepts (Milliseconds), and Error Rates (Percentages) for the Two Conditions of Experiment 1

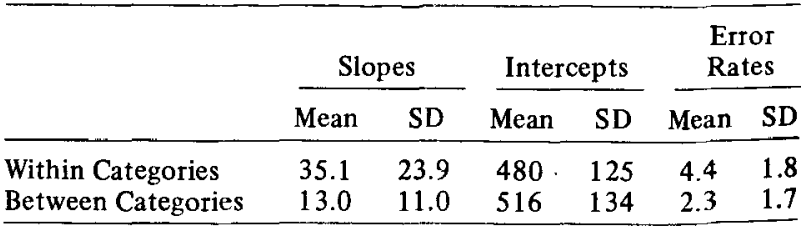


evidently treat this trial like any other betweencategory trial: they respond to a categorial difference regardless of which particular target produced that difference.

We analyzed the results from the 8 subjects who were discarded because of high error rates. The mean slopes for these subjects were 33.2 and $18.5 \mathrm{msec}$ per character for within- and between-category conditions, respectively $[\mathrm{t}(7)=1.95, \mathrm{p}<.05$, onetailed]. In short, the main results for these discarded subjects paralleled those obtained for the 16 subjects who met the error-rate criterion.

Unexpected between-category trial. Our main question was whether the category effect depends on subjects' set for a categorial difference between target and field items. This question is addressed by the result of the unexpected between-category trial that followed the 112 within-category trials. The following procedure was used to analyze these results.

As already described, for half of the subjects, the unexpected trial was of display size 2; for the other half, it was display size 5 . For each subject, we calculated the mean RTs for within- and between-category trials of the same display size as that subject received on the unexpected trial. Thus, for example, for subjects who received an unexpected trial of display size 2 , we calculated the mean reaction times of responses to display size 2 on the standard withinand between-category trials. These data, averaged across subjects, are plotted in Figure 1. By this procedure, display size is rendered a between-subject variable, since each subject contributes values to only one display size (corresponding to the display size of the unexpected trial that subject received).

To test the slope of the unexpected trial function against the slopes of the other two functions, we first matched pairs of subjects who had unexpected trials of different display sizes according to their overall reaction time on all trials. This resulted in eight "composite subjects," from each of whom we calculated slopes for the three functions shown in the figure. Analysis of variance of these slopes (now treated as a within-subject factor because of the matching procedure) demonstrated an overall main effect $[F(2,14)=4.34, p<.05]$. More importantly, however, the only individual slope comparisons to achieve significance by Newman-Keuls test (at the $p<.05$ level) were those of the standard within- vs. between-category trials, and of the standard withinvs. unexpected between-category trials. As is evident from the figure, the between-category and unexpected between-category functions are essentially parallel to one another.

We conclude that performance on the unexpected between-category trial mimics the performance on the standard between-category trials that follow it. In short, subjects do not have to expect a categorial

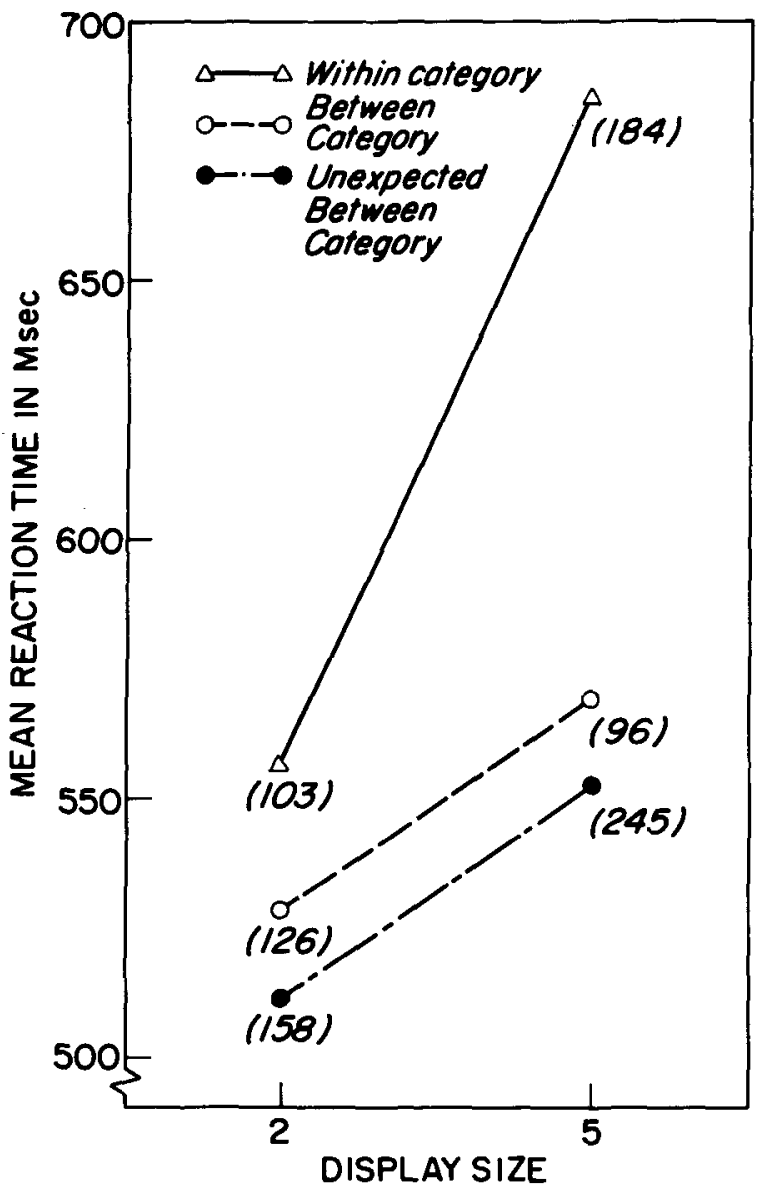

Figure 1. Mean reaction time (with standard deviations in parentheses) as a function of display size for within-category, between-category, and unexpected between-category trials of Experiment 1. Each subject contributes data to only one display size in the graph (see text for explanation).

difference between target and field items in order to produce the symptom most characteristic of the category-effect, lower search times per item in a between- than in a within-category condition. Set for categorial difference is evidently not necessary.

This result stands in clear contradiction to the assumption that the subjects "choose" to process partially or fully, depending upon their foreknowledge of the categorial condition. Recall that we were compelled to append this assumption to the partial processing hypothesis to let it encompass the oh-zero effect. As this assumption has proved to be false, so probably is the partial processing hypothesis itself.

The viability of the partial processing hypothesis has been attacked on other grounds as well. Thus, Dick (1971) and Nickerson (1973) mustered evidence suggesting that identification precedes categorization rather than the other way around as the partial processing hypothesis demands. In a different vein, 
Deutsch has sketched some nonempirical arguments against a featural description of the letter-digit distinction (Deutsch, 1977). Finally, there have been some demonstrations of category effects based on semantic criteria that are obviously troublesome for a (visual) featural theory (Karlin \& Bower, 1976; Lawrence, 1971). All of these arguments, taken together with the results of our Experiment 1, throw serious doubt upon the partial processing hypothesis. However, before considering alternatives to this hypothesis, we want to consider another possible effect of set.

\section{EXPERIMENT 2}

The results of Experiment 1 show that the performance difference between within- and betweencategory trials occurs regardless of subjects' expectations about the categorial condition. On the face of it, this seems to suggest that the category effect does not depend upon set. But this cannot be. After all, the oh-zero phenomenon is the clearest possible demonstration that set is crucial. This apparent contradiction is resolved by considering that set can here be manifested in another way. The important bit of pretrial information subjects need may concern not the categorial relationship between target and field items (that is, within- or between-category), but rather the category of the target itself (that is, letter or digit). In Experiment 1, we eliminated only the set for the categorial relationship between target and field items. A second experiment was performed to test the effects of eliminating the set for the category of the target.

To determine whether such a set for target category is necessary to produce the category effect, we devised a situation that made such a set impossible, or at least quite unlikely. Subjects were asked to look for two targets that belonged to two different categories. Thus they might be told that the two potential targets on a given trial are a $\mathrm{D}$ and a 4 . We reasoned that, under these conditions, the subject would not be able to adopt a consistently useful set for either category. As a result, there should be no category effect.

\footnotetext{
Method

General design. The design paralleled that of Experiment 1. Two blocks of within-category trials were followed by two blocks of between-category trials. After the within-category trials, the subjects encountered an unexpected between-category trial, just as they did in Experiment 1 . At the very end of the session, again as in Experiment 1, a catch-trial was administered.

Subjects. The twenty-four subjects whose data were included in the analysis were female undergraduates who were paid for participation in a 40 -min session. Four other female undergraduates were excluded from the main analysis due to excessively high error rates.
}

Apparatus and Stimulus materials. The stimulus cards and the apparatus were identical to those of Experiment 1, as were the orders in which the cards were presented.

The or:ly difference between the two experiments was in target specifications. While, in Experiment 1, either two letters or two digits were specified as potential targets on each trial, in the present experiment, one letter and one digit were specified as targets. The target specifications were arranged as follows: On trials on which a target appeared, the specified item that was not the target in Experiment 1 was replaced by a randomly chosen member of the population of targets from the opposite category. On trials on which no target appeared, one of the specified potential targets was deleted (balanced for order of specification) and replaced by a randomly chosen member of the target population of the opposite category.

Procedure. The subjects were given the same general instructions as in Experiment 1, except for being told that the two targets specified on each trial would be of different categories. For the within-category trials, subjects were informed that the field items would always be of the same category as the target; for between-category trials, they were told that the field items would be of a different category.

Four subjects were replaced because they failed to meet the error criterion of $7.5 \%$ on both the within- and between-category trials. These subjects averaged $9.6 \%$ errors on the former trials, $10.2 \%$ on the latter (SDs were 4.7\% and 2.1\%).

\section{Results}

The analysis of the results parallels that undertaken for the results of Experiment 1.

Standard within- and between-category trials. The category effect appears to be eliminated by the present procedure. Table 2 displays the means and standard deviations of the error rates and of the slopes and intercepts of the RT functions. As the table shows, the two categorial conditions produce virtually identical results $[\mathrm{t}(23)=.57, \mathrm{p}>.20$; $\mathrm{t}(23)=.47, \mathrm{p}>.20 ; \mathrm{t}(23)=.02, \mathrm{p}>.20$, respectively]. ${ }^{3}$

The overall effect of serial position of target specification in the present experiment is significant [505 vs. 532 msec: $F(1,23)=16.28, p<.01]$. There is, however, no substantial difference in the size of this effect for within- and between-category trials, as indicated by the absence of a reliable interaction between serial position and category condition $(F<1)$. The means are 512 and $533 \mathrm{msec}$ for the first and second serial positions, respectively, for the within-category trials, and 497 and $530 \mathrm{msec}$, respectively, for the between-category trials.

Further evidence that the subjects do not process

Table 2

Means and Standard Deviations for Slopes (Milliseconds per Character), Intercepts (Milliseconds), and Error Rates (Percentages) for the Two Conditions of Experiment 2

\begin{tabular}{|c|c|c|c|c|c|c|}
\hline & \multicolumn{2}{|c|}{ Slopes } & \multicolumn{2}{|c|}{ Intercepts } & \multicolumn{2}{|c|}{$\begin{array}{l}\text { Error } \\
\text { Rates } \\
\end{array}$} \\
\hline & Mean & SD & Mean & SD & Mean & SD \\
\hline Within Categories & 33.0 & 14.9 & 406 & 71.4 & 3.9 & 2.2 \\
\hline Between Categories & 30.9 & 14.3 & 406 & 63.1 & 3.6 & 1.9 \\
\hline
\end{tabular}


categorially on between-category trials comes from the result of the catch trial. In contrast to Experiment 1, only 4 of the 24 subjects responded to the between-category catch trial. This again suggests that processing in this condition is more similar to typical within- than between-category search.

We analyzed the results from the four subjects who were discarded because of high error rates. Although these analyses revealed the same trends evident for the subjects who met the error criterion, there were not sufficient data to establish meaningful tests of significance.

Unexpected between-category trial. This trial was included as a further check on the role of set in the event that a category effect had been obtained on the standard trials. Since no such effect was obtained, this unexpected trial turned out to be superfluous. Not surprisingly, no category effect was obtained with this trial either. We compared the results from this and the standard trials using the identical analysis employed in Experiment 1. As Figure 2 shows, the slopes of all three functionsstandard within-category, standard between-category, and unexpected between-category-were virtually identical $(F<1)$.

\section{GENERAL DISCUSSION}

The results of these experiments underline the point already made by the oh-zero study (Jonides \& Gleitman, 1972): The category effect is not a sole consequence of the stimulus shown but also depends on what the subject is looking for. The identical cards that produced a category effect in Experiment 1 did not do so under the changed instructional conditions of Experiment 2. The subject's set is clearly relevant. What matters is the set for a given target category rather than foreknowledge of the categorial conditions of the stimulus card.

How could this be so? We have previously criticized the partial processing hypothesis for predicting a set effect in Experiment 1 that did not materialize. Should we now resurrect this hypothesis, given the demonstraton in Experiment 2 that set does play a role in producing a category effect? The answer is no. For the simple fact is that the partial processing hypothesis implies one and only one kind of set effect in categorial visual search: the subject is presumed to choose between full and partial processing when faced with known within- and betweencategory trials, respectively. The hypothesis makes no prediction about the effect of knowledge of target category as such. Thus, the positive results of Experiment 2 are of little comfort to those who would maintain this hypothesis. It is certainly reasonable to cast about for a theoretical alternative.

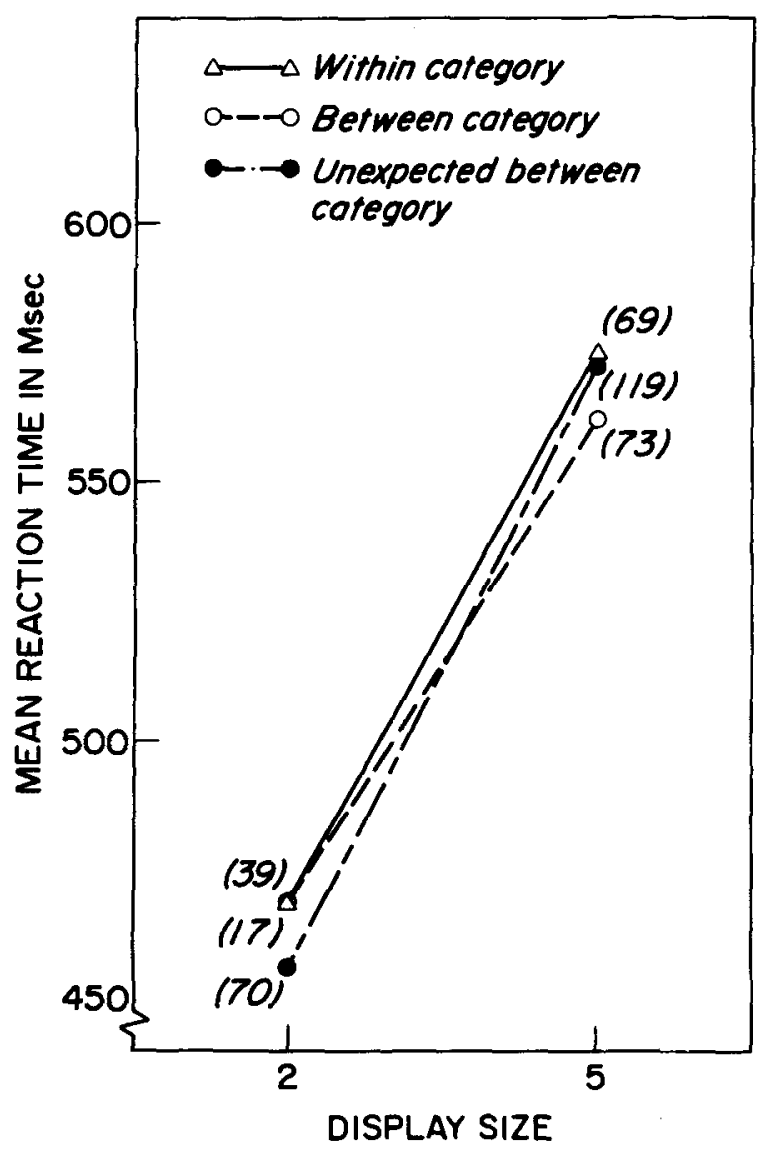

Figure 2. Mean reaction (with standard deviations in parentheses) as a function of display size for within-category, between-category, and unexpected between-category trials of Experiment 2. Each subject contributes data to only one display size in the graph (see text for explanation).

One possibility is to emphasize the conceptual as opposed to the perceptual aspects of category membership. ${ }^{4}$ The idea is that the category effect is produced by processing stages subsequent to the initial analysis of the visual array. According to this view, array items can be encoded both in terms of their identity (e.g., A vs. 4) and their category membership (e.g., letter vs. digit). The category-effect is here presumed to result from the processes which access these codes rather than from those which lay them down. Given this distinction between encoding and accessing operations, the question of whether identification codes are created before, after, or simultaneously with category codes is not relevant to the explanation of the category-effect. This effect is presumed to arise from some factor that allows easier access to the target's category code as well as its specific identity code.

This position rests on a distinction between early perceptual and later access and decision processes. Insofar as it emphasizes the role of the later stages, it resembles certain theories of selective attention 
(e.g., LaBerge, 1973; Norman, 1968) that are usually traced back to the position of Deutch and Deutch (1963).

How is this general approach relevant to the category effect? We need two assumptions. We will assume that when subjects are engaged in alphanumeric visual search they must access codes on both the category and identity levels. A further, and rather plausible, assumption concerns the time that is required to compare the representation of the target(s) the subjects look for with the display items in the array. The closer the match between thesein terms of the category and identity codes-the longer the comparison time. The category effect readily follows from these assumptions, since field items on within-category trials have more code overlap with searched-for targets than do field items on between-category trials. The same assumptions can also account for the result of the present experiments.

Since we assume that the comparison of target representations and display items requires the use of both category and identity codes (on both withinand between-category trials), the results of Experiment 1 follow. Between-category trials, whether expected or not, will yield shorter comparison times per item because of lower code overlaps (between target representations and field items) than will within-category trials. The situation is quite different in Experiment 2. There, the subjects' target representations include codes of both categories. But this means that, on between-category trials, a given display items' category code alone cannot possibly tell the search mechanism whether that item is or is not a target. As a result, the comparison times on between- and within-category trials have to be identical.

This interpretation can encompass the oh-zero effect as well. Let us merely assume that subjects encode the elliptical character " 0 " differentially, depending upon their set: when looking for "oh," they encode it as letter; when looking for "zero," they encode it as digit. Once encoded in one of these forms, it will be treated like other members of its category.

This line of reasoning explains the results of the present experiments and of prior studies (e.g., Gleitman \& Jonides, 1976; Jonides \& Gleitman, 1972 , 1976). But something is disquieting. Our theoretical analysis requires the assumption that subjects use the letter-digit category codes on withinas well as on between-category trials. But why should this be so, considering that the category code serves no discriminative function on within-category trials? We can only suggest that extended discriminative experience with letters and digits has rendered the associative arousal of their category codes inevitable.
In summary, two experiments were performed which demonstrate that the category effect is sensitive to change in the subject's set for the category of the targets but not the category of the field items. In conjunction with other findings, these results suggest that the locus of the effect is at the level of accessing codes rather than in the encoding processes themselves.

\section{REFERENCE NOTE}

1. Keren, G. Additional considerations of the "category" effect. Paper presented at the meeting of the Psychonomic Society, November 1977.

\section{REFERENCES}

Brand, J. Classification without identification in visual search. Quarterly Journal of Experimental Psychology, 1971, 23, 178-186.

DeUtch, J. A. On the category effect in visual search. Perception \& Psychophysics, 1977, 21, 590-592.

Deutch, J. A., \& Deutch, D. Attention: Some theoretical considerations. Psychological Review, 1963, 70, 80-90.

Dick, A. O. Processing time for naming and categorization of letters and numbers. Perception \& Psychophysics, 1971, 9, 350-352.

Egeth, H., Jonides, J., \& $W_{\text {ALL }}$, S. Parallel processing of multielement displays. Cognitive Psychology, 1972, 12, 278-286.

ERIKsen, C. W., \& Rohrbaugh, J. Some factors determining efficiency of selective attention. American Journal of Psychology, 1970, 83, 330-342.

Gleitman, H., \& Jonides, J. The cost of categorization in visual search: Incomplete processing of target and field items. Perception \& Psychophysics, 1976, 20, 281-288.

INGLING, N. W. Categorization: A mechanism for rapid information processing. Journal of Experimental Psychology, 1972, 94, 239-243.

Jonides, J., \& Gleitman, H. A conceptual category-effect in visual search: 0 as letter or as digit. Perception \& Psychophysics, 1972, 12, 457.460.

Jonides, J., \& Gleitman, $H$. The benefit of categorization in visual search: Target location without identification. Perception \& Psychophysics, 1976, 20, 289-298.

KarLiN, M. B., \& Bower, G. H. Semantic category effects in visual search. Perception \& Psychophysics, 1976, 19, 417-424.

LABERGE, D. Attention and the measurement of perceptual learning. Memory \& Cognition, 1973, 1, 268-276.

LAWRENCE. D. H. Two studies of visual search for word targets with controlled rates of presentation. Perception \& Psychophysics, 1971, 10, 85-89.

Nickerson, R. S. Can characters be classified directly as digits vs. letters or must they be identified first? Memory \& Cognition, 1973, 1, 477-484.

Norman, D. H. Towards a theory of memory and attention. Psychological Review, 1968, 75, 522-536.

PosNer. M. I. On the relationship between letter names and superordinate categories. Quarterly Journal of Experimental Psychology, 1970, 22, 279-287.

Sperling, G., Budiansky, J., Spivak, J. G., \& Johnson, M. C. Extremely rapid visual search: The maximum rate of scanning letters for the presence of a numeral. Science, 1971, 174, 307-311.

STERnBERG, S. High-speed scanning in human memory. Science, 1966, 153, 652-654. 


\section{NOTES}

1. This argument notwithstanding, we have run an experiment of the sort described in the text. The results confirmed the results of Experiment 1. The size of the category-effect was undiminished under conditions in which subjects had no advance knowledge of the categorial relationship between target and field items.

2. In order to insure that suspicions were not aroused by either the unexpected between-category trial or by the catch trial, the experimenter was careful to feign having made a procedural mistake after each of these trials was administered. The subjects appeared to accept this ruse quite nonchalantly. Of course, they were debriefed after the experiment was over, and they were urged not to expose the experimental procedure to other members of the subject population. No subject reported having been given advance information about the procedure.

3. We worried about the interpretation of the $2.1-\mathrm{msec} / \mathrm{character}$ difference in slope values between the conditions, even though this difference was small and unreliable. It might of course be simply the result of sampling error. But, alternatively, it might represent a small effect that could be attributed to either of two factors. One possibility is that it represents a residual category effect. Alternatively, it might be the result of a practice effect. This effect would be asymmetric, since the very point of the experiment forced us always to run the within-category trials first. To check on this possibility, we ran eight subjects in an experiment identical to Experiment 1, except that the between-category trials were administered first. This procedure led to a slope of $32.0 \mathrm{msec} / \mathrm{character}$ for the within-category condition, and $34.8 \mathrm{msec} / \mathrm{character}$ for the between-category condition, a nonsignificant reversal of the original effect $[t(7)=0.37 ; p>.20]$. We conclude that the original difference of $2.1 \mathrm{msec} / \mathrm{character}$ was not a residual category effect.

4. We are deeply indebted to James $L$. McClelland for his extensive and incisive theoretical discussion of the results of these experiments. He convinced us that the interpretation proposed here is superior to other theoretical alternatives we had previously considered.

(Received for publication September 9, 1977; revision accepted August 1, 1978.) 